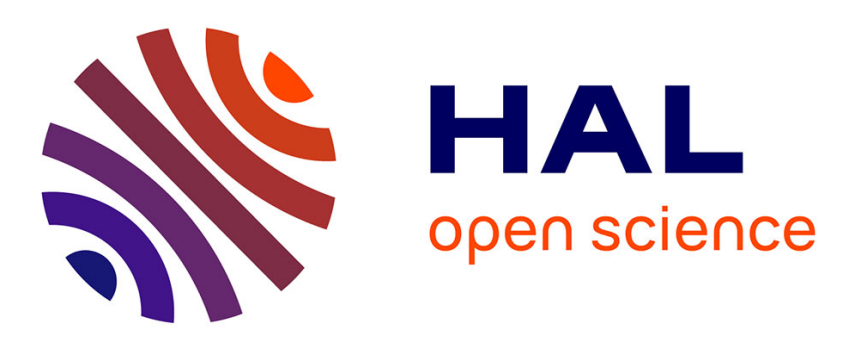

\title{
Isochronous analysis of the behaviour of ceramic-matrix composites under thermomechanical cyclic loading conditions
}

\author{
Alain Burr, François Hild, Frederick A Leckie
}

\section{> To cite this version:}

Alain Burr, François Hild, Frederick A Leckie. Isochronous analysis of the behaviour of ceramic-matrix composites under thermomechanical cyclic loading conditions. Composites Science and Technology, 2001, 61 (15), pp.2231-2238. 10.1016/S0266-3538(01)00117-8 . hal-02342797

\section{HAL Id: hal-02342797 \\ https://hal.science/hal-02342797}

Submitted on 4 Nov 2019

HAL is a multi-disciplinary open access archive for the deposit and dissemination of scientific research documents, whether they are published or not. The documents may come from teaching and research institutions in France or abroad, or from public or private research centers.
L'archive ouverte pluridisciplinaire HAL, est destinée au dépôt et à la diffusion de documents scientifiques de niveau recherche, publiés ou non, émanant des établissements d'enseignement et de recherche français ou étrangers, des laboratoires publics ou privés. 


\title{
ISOCHRONOUS ANALYSIS OF THE BEHAVIOR OF CERAMIC-MATRIX COMPOSITES UNDER THERMOMECHANICAL CYCLIC LOADING CONDITIONS
}

by

Alain BURR, François HILD and Frederick A. LECKIE

\begin{abstract}
The design of parts made of Ceramic-Matrix Composites needs computations in fatigue and creep. Micromechanical analyses under monotonic loading conditions have been integrated within the framework of Continuum Thermodynamics. The extension to creep and/or fatigue loadings leads to a description of the state of the material with a large number of internal variables. In the present paper, an isochronous approach is presented in order to decrease this number, and therefore to give an answer with nowadays computational facilities in a time equivalent to monotonic loading conditions. The main objective of this paper is to present and illustrate an original method that allows the designer to simplify the computation of the long time analyses (i.e., fatigue, creep) to reduce the CPU time down to a monotonic analysis.
\end{abstract}

Keywords: ceramic-matrix composite, creep, fatigue, isochronous analysis, finite element computations. 


\section{INTRODUCTION}

Composites consisting of a ceramic matrix reinforced by continuous ceramic fibers are candidates for application in components which operate at temperatures in excess of those which are normal for metallic structures. In spite of the fact that the constituents of the Ceramic-Matrix Composite (CMC) are both brittle it has been demonstrated that following matrix-cracking, sliding occurs at the fiber-matrix interface which causes inelastic strains [1]. The presence of matrix cracks and inelastic deformations may impart to the material the ability to redistribute stresses. The ability to redistribute stress is an important property since design studies indicate that combined working stresses and temperatures for CMC components are sufficiently high for matrix-cracking to be unavoidable in regions of stress concentration occurring at the junctions and penetrations which are a feature of engineering components.

A constitutive law is proposed for CMCs that models matrix-cracking, interface sliding and wear [2], fiber breakage [3], fiber pull-out and creep [4]. These different mechanisms induce loss of stiffness [5,6], inelastic strains [7,8], creep strains, hysteresis loops, and crack closure. The features are analyzed within the framework of Continuum Damage Mechanics (CDM) [9] by the introduction of physical internal variables identified previously in Material Science investigations. By combining CDM with micromechanical studies which are mechanism-based, constitutive equations are developed [10], which lend themselves to the finite element procedures commonly used in practice.

The first part will present the principal results of the construction of a constitutive law to model the behavior under monotonic loadings within the framework of CDM. The second and the third parts are the extensions of the model to account for fatigue and creep, respectively. The model is integrated into a finite element system (ABAQUS) and is used to estimate the behavior of a

representative structure under monotonic, cyclic and creep loading conditions. Design and lifing procedures are able to deal with thermal loading, creep and cyclic loading, just by extending the original software to Isochronous Analysis. It is observed that some CMCs have the ability to redistribute stresses. It follows that, as it is for plasticity, the presence of an initial stress 
concentration does not compromise the performance of the component, because it is reduced during the loading.

\section{MECHANICAL BEHAVIOR UNDER MONOTONIC LOADINGS}

In this part, the results of the construction of a multi-axial constitutive equation are briefly summarized. They are based upon micromechanical studies of matrix-cracking, fiber/matrix interface debonding and sliding as well as fiber breakage and pull-out in CMCs. These active mechanisms are reformulated by using the CDM formalism, which is more appropriate to be integrated into a Finite Element code. This study is primarily concerned with $(0,90)$ fiber architectures embedded in a matrix (e.g., laminated and woven composites). The detail of the full construction of this constitutive equation [10] can be summarized by the expression of the free energy density, $\psi$.

The initial behavior of the matrix is assumed to be isotropic. The presence of cracks leads the behavior to become anisotropic. The assumption is made that cracking occurs normal to the ydirection (e.g. maximum principal strain direction) in the matrix. Under the hypothesis of monotonic loading condition, only one damage variable is needed to model matrix-cracking, and is denoted by $\mathrm{D}_{\text {iny }}$. The study of a cracked system normal to one direction shows that the Young's modulus along that direction as well as the shear modulus are altered and that the expression of the elastic energy density of the matrix is

$$
\psi_{\mathrm{m}}=\frac{1}{2} \frac{\mathrm{E}_{\mathrm{m}}\left[\varepsilon_{\mathrm{mxx}}^{2}+2 v_{\mathrm{m}}\left(1-\mathrm{D}_{\mathrm{my}}\right) \varepsilon_{\mathrm{mxx}} \varepsilon_{\mathrm{myy}}+\left(1-\mathrm{D}_{\mathrm{my}}\right) \varepsilon_{\mathrm{myy}}^{2}\right]}{1-v_{\mathrm{m}}^{2}\left(1-\mathrm{D}_{\mathrm{my}}\right)}+2 \widetilde{\mathrm{G}}_{\mathrm{m}}\left(\mathrm{D}_{\mathrm{my}}\right) \varepsilon_{\mathrm{mxy}}^{2}
$$

with

$$
\tilde{G}_{m}\left(D_{m y}\right)=\frac{G_{m}}{1+\left(\frac{D_{m y}}{1-D_{m y}}\right) \frac{1}{2\left(1+v_{m}\right)}}
$$

where $E_{m}, v_{m}, G_{m}$ are the initial elastic properties of the matrix. The components of the strain tensor of the matrix $\underline{\underline{\varepsilon}}_{\mathrm{m}}$ expressed in the $\mathrm{x}-\mathrm{y}$ frame are denoted by $\varepsilon_{\mathrm{mxx}}, \varepsilon_{\mathrm{myy}}$ and $\varepsilon_{\mathrm{mxy}}$. 
The fibers are aligned along the 1-direction. The fiber breaks are assumed to be perpendicular to the fiber direction and described by a damage parameter $\mathrm{D}_{\mathrm{fl}}$. Therefore the elastic energy density of the fibers is given by

$$
\psi_{\mathrm{f}}=\frac{1}{2}\left[\mathrm{E}_{\mathrm{f}}\left(1-\mathrm{D}_{\mathrm{f} 1}\right) \varepsilon_{\mathrm{f} 11}^{2}+\mathrm{E}_{\mathrm{f}} \varepsilon_{\mathrm{f} 22}^{2}\right]+2 \tilde{\mathrm{G}}_{\mathrm{f}}\left(\mathrm{D}_{\mathrm{f} 1}\right) \varepsilon_{\mathrm{f} 12}^{2}
$$

with

$$
\tilde{G}_{f}\left(D_{f 1}\right)=\frac{G_{f}}{1+\left(\frac{D_{f 1}}{1-D_{f 1}}\right) \frac{1}{2\left(1+v_{f}\right)}}
$$

where $E_{f}, v_{f}, G_{f}$ are the initial elastic properties of the fiber. The components of the strain tensor of the fiber $\underline{\varepsilon}_{\mathrm{f}}$ expressed in the $\mathrm{x}-\mathrm{y}$ frame are denoted by $\varepsilon_{\mathrm{f} 11}, \varepsilon_{\mathrm{f} 22}$ and $\varepsilon_{\mathrm{f} 12}$.

A layer consists of fibers aligned along the 1-direction embedded in the matrix. To determine the behavior of this layer, micro-interface compatibility conditions are written in terms of strains $\underline{\varepsilon}^{\mathrm{L}}$ and stresses $\underline{\sigma}^{\mathrm{L}}$ on the layer level. It is more convenient to write the conditions in the 1-2 frame. The following equations are derived by using Voigt's approximation in the fiber direction and Reuss' approximation for the transverse properties

$$
\begin{array}{ccc}
\varepsilon_{\mathrm{m} 11}=\varepsilon_{\mathrm{f} 11}=\varepsilon_{11}^{\mathrm{L}} & \mathrm{f}_{\mathrm{m}} \varepsilon_{\mathrm{m} 22}+\mathrm{f}_{\mathrm{f}} \varepsilon_{\mathrm{f} 22}=\varepsilon_{22}^{\mathrm{L}} & \mathrm{f}_{\mathrm{m}} \varepsilon_{\mathrm{m} 12}+\mathrm{f}_{\mathrm{f}} \varepsilon_{\mathrm{f} 12}=\varepsilon_{12}^{\mathrm{L}} \\
\mathrm{f}_{\mathrm{m}} \sigma_{\mathrm{m} 11}+\mathrm{f}_{\mathrm{f}} \sigma_{\mathrm{f} 11}=\sigma_{11}^{\mathrm{L}} & \sigma_{\mathrm{m} 22}=\sigma_{\mathrm{f} 22}=\sigma_{22}^{\mathrm{L}} & \sigma_{\mathrm{m} 12}=\sigma_{\mathrm{f} 12}=\sigma_{12}^{\mathrm{L}}
\end{array}
$$

where $f_{f}, f_{m}$ denote the volume fraction of the fiber and the matrix, respectively, $\sigma_{i j}^{L}$ and $\varepsilon_{i j}^{L}$ are the components of the stress and strain tensors $\underline{\sigma}^{\mathrm{L}}$ and $\underline{\underline{\varepsilon}}^{\mathrm{L}}$ in the 1-2 frame. The solution of the previous system yields

$$
\stackrel{\sigma}{\sigma}^{\mathrm{L}}=\underline{\underline{E}}^{\mathrm{L}}\left(\mathrm{D}_{\mathrm{my}}, \mathrm{D}_{\mathrm{f} 1}\right): \underline{\varepsilon}^{\mathrm{L}}
$$

where $\underset{\equiv}{E^{L}}\left(D_{m y}, D_{f 1}\right)$ is the stiffness tensor of a layer which is dependent upon all damage variables defined at the constituent level. The elastic energy density associated to matrix cracking and fiber breakage at the layer level is expressed as 


$$
\psi^{\mathrm{L}}=\frac{1}{2} \underset{\varepsilon^{\mathrm{L}}}{=}:{\underset{\equiv}{\underline{E}}}^{\mathrm{L}}\left(\mathrm{D}_{\mathrm{my}}, \mathrm{D}_{\mathrm{f} 1}\right): \underline{\underline{\varepsilon}}^{\mathrm{L}}
$$

The elastic behavior of a $(0,90)$ composite system is determined by applying classical laminate theory

$$
\underline{\underline{\varepsilon}}=\underline{\underline{\varepsilon}}^{00}=\underline{\underline{\varepsilon}}^{90} \text { and } \quad \underline{=}=\mathrm{f}^{00} \underline{\sigma}^{00}+\mathrm{f}^{90} \underline{\sigma}^{90}
$$

where $\mathrm{f}^{00}$ and $\mathrm{f}^{90}$ denote the volume fraction of the 0 and 90 degree layers, $\underline{\varepsilon}^{00}, \underline{\sigma}^{00}$ and $\underline{\varepsilon}^{90}, \underline{\sigma}^{90}$ the strain and stress tensors in the 0 and 90 degree layers, respectively. The overall behavior of the composite is defined as

$$
\underline{\underline{\sigma}}=\underset{\equiv}{\underline{E}}\left(\mathrm{D}_{\mathrm{my}}^{00}, \mathrm{D}_{\mathrm{my}}^{90}, \mathrm{D}_{\mathrm{f} 1}^{00}, \mathrm{D}_{\mathrm{fl}}^{90}\right): \underline{\underline{\varepsilon}}
$$

with

$$
\underset{\equiv}{\underline{E}}\left(D_{m y}^{00}, D_{m y}^{90}, D_{f 1}^{00}, D_{f 1}^{90}\right)=f^{00} \underset{\equiv}{E}\left(D_{m y}^{00}, D_{f 1}^{00}\right)+f^{90} \underset{\equiv}{E}\left(D_{m y}^{90}, D_{f 1}^{90}\right)
$$

where $\underset{\equiv}{\mathrm{E}}\left(\mathrm{D}_{\mathrm{my}}^{00}, \mathrm{D}_{\mathrm{my}}^{90}, \mathrm{D}_{\mathrm{fl}}^{00}, \mathrm{D}_{\mathrm{f} 1}^{90}\right)$ is the fourth order elastic tensor of the composite, which is a function of all damage variables on the constituent level for all layers. The elastic energy density associated with matrix-cracking and fiber breakage can be written on the composite level

$$
\psi^{D}=f^{00} \psi^{00}+f^{90} \psi^{90}
$$

where $\psi^{00}$ and $\psi^{90}$ are the elastic energy densities of the 0 and 90 degree layers, respectively.

Inelastic strains are essentially due the interface sliding between the fiber and the matrix. From a micromechanical point of view, sliding can take place as soon as a crack is bridged by fibers. The analysis of these sliding systems leads to the following expression of the stored energy density [5]

$$
\psi^{S}=\frac{1}{2} E\left(\frac{\varepsilon_{i 11}^{2}}{d_{11}}+\frac{\varepsilon_{i 22}^{2}}{d_{22}}\right)+\frac{1}{2} G\left(\frac{\varepsilon_{i 12}^{2}}{d_{12}}\right)
$$

with 


$$
E=\frac{4}{3} \frac{f^{00} E^{00} f^{90} E^{90}}{f^{00} E^{00}+f^{90} E^{90}} \quad \text { and } \quad G=\frac{f^{00} G^{00} f^{90} G^{90}}{f^{00} G^{00}+f^{90} G^{90}}
$$

where $\mathrm{E}^{00}$ is the Young's modulus of the 0 degree layer in the fiber direction, $\mathrm{E}^{90}$ is the Young's modulus of the 90 degree layer in the fiber direction, $\mathrm{G}^{00}$ is the shear modulus of the 0 degree layer, $G^{90}$ is the shear modulus of the 90 degree layer, $d_{11}, d_{22}$ and $d_{12}$ are damage quantities related to sliding, $\varepsilon_{\mathrm{i} 11}, \varepsilon_{\mathrm{i} 22}$ and $\varepsilon_{\mathrm{i} 12}$ are the inelastic strains. The following expression of the free energy density for $(0,90)$ CMCs can thus be obtained

$$
\psi=\frac{1}{2}\left(\underline{\underline{\varepsilon}}-\underline{\varepsilon_{\mathrm{i}}}\right): \underset{\equiv}{\mathrm{E}}\left(\mathrm{D}_{\mathrm{mx}}^{00}, \mathrm{D}_{\mathrm{mx}}^{90}, \mathrm{D}_{\mathrm{f} 1}^{00}, \mathrm{D}_{\mathrm{f} 1}^{90}\right):\left(\stackrel{\varepsilon}{=}-\varepsilon_{\mathrm{f}}\right)+\psi^{\mathrm{S}}
$$

From this expression, the associated forces to each internal variable are given by partial differentiation

$$
\underline{\underline{\sigma}}=\frac{\partial \psi}{\partial \underline{\underline{\varepsilon}}} \quad, \quad Y=-\frac{\partial \psi}{\partial \mathrm{D}}, \quad \mathrm{y}=-\frac{\partial \psi}{\partial \mathrm{d}} \quad \text { and } \quad \underline{X}=-\frac{\partial \psi}{\partial \underline{\underline{\varepsilon}}}
$$

where $\mathrm{D}=\left\{\mathrm{D}_{\mathrm{mx}}^{00} ; \mathrm{D}_{\mathrm{mx}}^{90} ; \mathrm{D}_{\mathrm{f} 1}^{00} ; \mathrm{D}_{\mathrm{f} 1}^{90}\right\}$ and $\mathrm{Y}=\left\{\mathrm{Y}_{\mathrm{mx}}^{00} ; \mathrm{Y}_{\mathrm{mx}}^{90} ; \mathrm{Y}_{\mathrm{f} 1}^{00} ; \mathrm{Y}_{\mathrm{f} 1}^{90}\right\}, \mathrm{d}=\left\{\mathrm{d}_{11} ; \mathrm{d}_{22} ; \mathrm{d}_{12}\right\}$ and $y=\left\{y_{11} ; y_{22} ; y_{12}\right\}$. A priori, it is necessary to know ten evolution laws associated to the ten internal variables. But, only the four following evolution laws are necessary:

- one law related to matrix cracking $D_{m}=D_{m}\left(Y_{m}\right)$, because the variables $D_{m y}^{00}$ and $D_{m y}^{90}$ correspond to only one single mechanism, and therefore have the same evolution law

$$
D_{\mathrm{m}}=\mathrm{D}_{\text {sat }}\left(1-\exp \left[-\left(\frac{\mathrm{Y}_{\mathrm{m}}}{\mathrm{Y}_{\mathrm{m} 0}}\right)^{\mathrm{m}_{\mathrm{m}}}\right]\right)
$$

- one law related to fiber breakage $\mathrm{D}_{\mathrm{f}}=\mathrm{D}_{\mathrm{f}}\left(\mathrm{Y}_{\mathrm{f}}\right)$, since $\mathrm{D}_{\mathrm{f} 1}^{00}$ and $\mathrm{D}_{\mathrm{f} 1}^{90}$ have the same evolution law, because fiber breaks are perpendicular to the fiber direction

$$
D_{f}=1-\exp \left[-\left(\frac{Y_{f}}{Y_{f 0}}\right)^{\left(m_{f}+1\right) / 2}\right] ;
$$

- two laws related to the inelastic strains, since debonding and sliding mechanisms in the 0 and 90 degree layers are identical, thus $\varepsilon_{\mathrm{i} 11}$ and $\varepsilon_{\mathrm{i} 22}$ have the same evolution law. The second one 
concerns $\varepsilon_{\mathrm{i} 12}$. In a unidimensional analysis $[11,12]$ it has been observed that the back stress $\underset{=}{\mathrm{X}}$

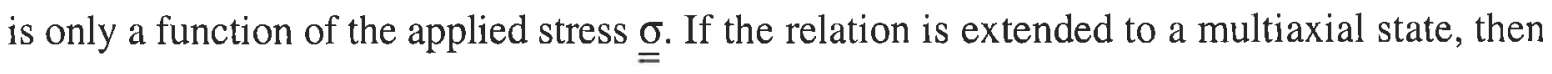
the inelastic strain tensor $\underline{\underline{\varepsilon}}_{\mathrm{j}}$ is a function of the stress tensor $\underline{\underline{\sigma}}$

$$
\varepsilon_{\mathrm{i} \alpha \alpha}=\varepsilon_{\mathrm{it}}\left(\frac{\left\langle\sigma_{\alpha \alpha}-\sigma_{\mathrm{th}}\right\rangle}{\sigma_{\mathrm{th}}}\right)^{\mathrm{n}_{\mathrm{t}}} \text { and } \varepsilon_{\mathrm{i} 12}=\varepsilon_{\mathrm{is}}\left(\frac{\left\langle\tau_{\mathrm{eq}}-\tau_{\mathrm{th}}\right\rangle}{\tau_{\mathrm{th}}}\right)^{\mathrm{n}_{\mathrm{s}}} \operatorname{Sign}\left(\sigma_{12}\right) \text {, }
$$

with an equivalent shear stress dependent upon the hydrostatic pressure

$$
\tau_{\mathrm{eq}}=\sqrt{\left|\sigma_{12}\left[\sigma_{12}+\frac{3}{2}\left(\sigma_{11}+\sigma_{22}\right)\right]\right|}
$$

where $\alpha \alpha=11,22$ and $\langle$.$\rangle are the Macauley brackets ;$

- two laws related to in-plane debonding $d=d(y), d_{11}$ and $d_{22}$ are assumed to have the same evolution law. These last evolution laws are not necessary to derive the behavior of the composite. Neither the state laws nor the evolution laws are explicit functions of the damage variables $d$ which are needed to express the stored energy.

The identification procedure is carried out by using the results of pure tension tests along two orientations: one in the direction of a set of fibers $\left(0^{\circ}\right)$ and one at $\pm 45^{\circ}$. Each test involves a series of loading and unloading sequences. The evolution laws were first identified on a laminated $\mathrm{SiC} / \mathrm{SiC}$ composite [13] and a woven one [14], then on an Oxide/Oxide composite (woven $\mathrm{Al}_{2} \mathrm{O}_{3} / \mathrm{Al}_{2} \mathrm{O}_{3}$ ). In the following, the constitutive equation corresponds to a $(0,90)$ woven $\mathrm{SiC} / \mathrm{SiC} \mathrm{CMC}$ processed by Dupont de Nemours (Appendix 1).

\section{EXTENSION TO CYCLIC LOADINGS}

Microscopic examinations of $\mathrm{SiC} / \mathrm{SiC}$ composites subjected to fatigue loading in excess of the matrix-cracking stress indicate that matrix-cracking and fiber/matrix interface debonding and slip remain the dominant mechanisms [15]. Under cyclic conditions the interface shear strength decreases 
because of interface wear [2]. A consequence of the reduced interface strength is a transfer of stress from the matrix on to the fiber causing an increase of the inelastic (ratchetting) strains with the number of cycles $[16,17]$.

Since the mechanism responsible for the increase of the inelastic strain with the number of cycles was first identified to be the wear of the fiber/matrix interface [2], the key idea is based upon the (sudden) variation of the interfacial shear stress between the fiber and the matrix from $\tau_{0}$ to $\tau_{\infty}$ (with $\tau_{0}>\tau_{\infty}$ ), when reverse sliding direction between the fiber and the matrix occurs the first time.

\subsection{Construction and Identification of Kinetic Laws in Fatigue}

A micromechanical analysis [17] pointed out the parameters which are important in deriving the kinetics of the inelastic strains as a function of the number of cycle

$$
\frac{\varepsilon_{i \alpha \beta}}{\varepsilon_{i \alpha \beta}(N)}=1-F[N]
$$

where $\varepsilon_{i \alpha \beta}(N)$ is the inelastic strain after $N$ cycles and $\varepsilon_{i \alpha \beta}$ the inelastic strain for the first loading $(\mathrm{N}=0)$. The function $\mathrm{F}[\mathrm{N}]$ utilized for the identification of the tests is

$$
\mathrm{F}[\mathrm{N}]=\gamma\left(1-\exp \left[-\left(\frac{\log [\mathrm{N}+1]}{\mathrm{a}}\right)^{\mathrm{n}}\right]\right)
$$

where $\gamma$ denotes the wear interface parameter, $\gamma=\left(\tau_{0}-\tau_{\infty}\right) /\left(\tau_{0}+\tau_{\infty}\right)$. Four-point bend tests (specimen loaded in the fiber direction) were used for the current identification. The symbols in Fig. 1 correspond to the maximum and minimum values of the inelastic strain, respectively, at the maximum and minimum stress levels, as a function of the number of cycles, $\mathrm{N}$. The identification of the kinetics of the inelastic strains was performed by using the maximum stress level. The minimum value of the inelastic strain is a prediction by assuming that the interfacial behavior is modeled by a constant interface shear strength. In that case, the minimum value is half of the maximum value $[1,6]$.

For cyclic loadings, the behavior of the CMCs is only exactly described when the load is proportional, and when the maximum and minimum stresses remain constant from one cycle to another one. The computation of the cyclic inelastic strain is obtained, from the monotonic inelastic 
strains, by a multiplication factor that depends on the number of cycles (Eqn. 21). In that particular case, for a given number of cycle, $\mathrm{N}$, the result given by the computation and the measurements are strictly equivalent. Therefore, the result of a computation for $\mathrm{N}$ cycles is the same than a monotonic computation 'distorted at N-cycle', according to the multiplication factor (Eqn. 22).

For the complete description of a loop for a given cycle $\mathrm{N}$, the full integration of the constitutive law needs to be performed. The advantage of this approach is that the first $\mathrm{N}-1$ cycles are quickly computed, but the details of cycle $\mathrm{N}$ can also be evaluated. The technique of computation is called an 'isochronous' analysis because the time is virtually suspended during the computation. It can be repeated for any number of cycles, which makes the computation very effective for large number of cycles. For a structure, the complexity of the stress redistribution is not exactly reproduced as the number of cycles increases. However, this simplified approach was tested successfully in a 4point bend test (Fig. 1). The inspection of the evolution of the stress profile through the thickness of the specimen as a function of the number of cycles (Fig. 2) shows that the first cycle gives the overall shape of that profile. This means that there is very little stress redistribution in this test during cycling, even if the strains are evolving.

\subsection{Validation on a Plate with a Hole Subjected to Remote Tension}

To carry out structural calculations, the model presented herein has been implemented in the industrial code ABAQUS [18] via a user material UMAT subroutine. In the following, the geometry of the tested specimen is $38 \mathrm{~mm}$ in width, for a thickness of $2.4 \mathrm{~mm}$ and a length of $102 \mathrm{~mm}$. The diameter of the hole corresponds to the half-width of the specimen, located at the center of the plate. The CPU time used in the case of a 6000 degree of freedom mesh is of the order of one minute on an HP735 workstation.

The specimen was tested in the direction of the fiber in tension between 0 and a maximum value of load (load ratio $\mathrm{R}=0$ ). The specimen did not fail. A series of 9 gauges was placed on specific points of the specimen. At critical places, several gauges were doubled the confirm the measurements, and to be sure that bending due to gripping is minimized. Figure $3 a$ shows the measurement (e.g. dots) up to 100000 cycles, which are compared to the computations, for the same location of various strain gauges (Fig. 3b). There is a good correlation between the measurements 
and the predictions. The measurement performed near the stress concentration of the hole (gauges 4 et 5) are under estimated by the computation by about $5 \%$. The conditions of the test was not perfect, because the response of gauges 3 and 6 are different, even though they should have been identical. However, the computation and the measurements are close enough to validate the approach and the experiment.

\subsection{Stress Redistribution in Fatigue}

Figure 4 shows that the stress concentration factor near the hole exhibits a drop of $10 \%$ after 10 thousand cycles, and $20 \%$ after 1 million cycles. Even after 1 million cycles, the stress profile is not stabilized yet and the stress concentration factor is equal to 1.4. This means that the stress-strain curve near the stress concentration must be still evolving. However, this change slows down as the number of cycles increases. During cycling, matrix-cracking and interface debonding and sliding allows part of the stress concentration due to the presence of the hole to be accommodated. This result is favorable for the design of structures in fatigue. Should fiber breakage occur, this conclusion would probably be less positive [19].

In summary, the numerical results under cyclic loading conditions (four-point bending, plate with a hole in remote tension) were obtained for a computation time comparable with a monotonic analysis. Furthermore, they give a complete set of information on the state of strain, stress and damage in the composite, which can be directly used in classical design rules of more complex structures. The fast computation enables the designer to analyze more cases, and can fully integrated in the optimization process of a structure or a part made of CMCs. This approximate procedure has the advantage that the stress and strain fields in a structural component for a given number of cycles $\mathrm{N}$ can be found directly without the need to perform a cycle by cycle calculation. The computation time is therefore the same as that for monotonic loadings by 'suspending' the time, or the number of cycles. The next part will show how to use the same techniques with creep. 


\section{EXTENSION TO CREEP CONDITIONS}

In the present case, the time and temperature are virtually 'suspended.' Creep laws are written according to micromechanical models in which only the matrix exhibits a creep component of strain of Norton type $[20,21]$. Consequently, the composite exhibits the same Norton type of behavior when subjected to creep tests.

\subsection{Formulation and Identification}

In this approach, only the matrix is considered to be creeping. It means that the material is used well below the creeping temperature of the fibers. The following expression of the free energy density for $(0,90)$ CMCs can thus be generalized

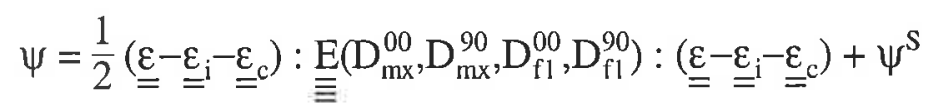

where $\underline{\underline{\varepsilon}}_{c}$ is the creep strain tensor. From this expression, the associated force $\underline{\underline{S}}$ to the creep strain is given by partial differentiation

$$
\underline{\underline{S}}=-\frac{\partial \psi}{\partial \underline{\underline{\varepsilon}}_{\mathrm{c}}}
$$

There are two different creeping mechanisms. The first one is activated when the CMC is subjected to a constant stress level in the fiber direction. Because creep occurs in the matrix, there is a time dependent transfer of stress from the matrix on to the fibers until the fibers in the loading direction of the stress carry all of the applied stresses. The creep strains in the fiber directions, $\varepsilon_{c \alpha \alpha}$, are limited by the elastic strain of a series of fibers ( 0 or 90 degrees). We use a generalized Arrhenius function that accounts for a large range of time scale. In the range of considered temperatures $\left(\mathrm{T}<1200^{\circ} \mathrm{C}\right)$, the elastic properties are supposed to be constant with temperature. This remark leads to the following possible expression for $\varepsilon_{\text {c } \alpha \alpha}$

$$
\varepsilon_{c \alpha \alpha}[t]=\frac{2 \sigma_{\alpha \alpha}}{f_{f} E_{f}}\left(1-\exp \left[-\left(\frac{t}{t_{i 0}}\right)^{n}\right]\right)
$$


where $n_{t}$ is the exponent of the creep law, $t_{i 0}$ is a normalizing time scale, and the ratio $2 \sigma_{\alpha \alpha} / f_{f} E_{f}$ is a creep strain amplitude controlled by the elasticity of the fiber alone. It is worth noting that the first order expansion of Eqn. (25) leads to an expression of Norton's law, which gives even more credit to the presence of exponent $n_{t}$. As the elastic properties do not vary much with temperature, we decided not to include the temperature explicitly in the expression of $\varepsilon_{c \alpha \alpha}$. This assumption was correlated by experiments $\left(\mathrm{T}<1200^{\circ} \mathrm{C}\right.$, no fiber creep). The parameters $\mathrm{n}_{\mathrm{t}}$ and $\mathrm{t}_{\mathrm{i} 0}$ are probably dependent on the temperature, but there were not enough coupons to perform all the necessary tests. Consequently, they are assumed to be constant with the temperature.

When the CMC is subjected to a constant tensile stress at \pm 45 degrees with respect to the fiber direction, a micromechanical analysis demonstrates that there is only a small stress transfer between the matrix and the fibers. Consequently, the shear stress is applied directly to the matrix which then creeps without constraint from the fibers. The creep strains in a ceramic follow a similar law as those used for metals [22]. The expression of the creep shear strain $\varepsilon_{\mathrm{c} 12}$ is written as

$$
\varepsilon_{c 12}[\mathrm{t}]=\varepsilon_{120} \exp \left[\mathrm{b}\left(\frac{\mathrm{T}}{\mathrm{T}_{0}}-1\right)\right]\left(\frac{\sigma_{12}}{\tau_{0}}\right)^{\mathrm{n}}\left(\frac{\mathrm{t}}{\mathrm{t}_{120}}\right)^{\mathrm{n}_{\mathrm{s}}}
$$

where the reference ' 0 ' is related to a normalizing test, which should be as close as possible to the operation conditions of the shear stress $\sigma_{12}$, temperature $\mathrm{T}$ and time $\mathrm{t}$. The parameters $\varepsilon_{\mathrm{c} 12}$ and $\mathrm{b}$ are amplification coefficients, and $n_{\sigma}$ et $n_{s}$ are exponents corresponding to a generalization of Norton's law applied to CMCs. By inspection of the material parameters (Appendix 1), one can notice that the time exponent is the same for both creep strains (tensile and shear). The big difference comes from the dependence in terms of stresses. When the tensile creep strain is proportional to the stress, the creep shear strain follows a power law with an exponent of 4.5 which high. Therefore shear stresses are very severe when creep is concerned.

\subsection{Application to a Plate with a Hole}

The geometry of the specimen is identical to the one used in the fatigue test (loading at \pm 45 degrees with respect to the fiber directions). The profile of normal stresses in the ligament of the plate with a hole heated at $980^{\circ} \mathrm{C}$ and under an average stress of $50 \mathrm{MPa}$ shows very little redistribution as 
time proceeds (Fig. 5). The same plate for a temperature of $1200^{\circ} \mathrm{C}$ with the same average stress in the ligament experiences a drop of $25 \%$ of the stress concentration factor after 200 hours (Fig. 6). It is worth noting that the stress redistribution is faster at the beginning of the loading time. Even after 200 hours, it does not tend to a uniform distribution in the ligament. The stress concentration factor is still equal to 1.4. However, this computation does not account for fiber creep. Creep experiments show that for higher temperature $\left(\mathrm{T}=1300^{\circ} \mathrm{C}\right)$, fibers are exhibiting creep [23] and were confirmed by a few of the present data. It will be then necessary to integrate this information in the evolution law by modifying the expression of the creep strain in the direction of the fibers ( 0 or 90 degrees) $\varepsilon_{\text {cax }}$.

The case of coupled fatigue/creep can be obtained by considering in isochronous analyses in both fatigue and creep cases with a coupling coefficient relative to the 'suspended' time and temperature.

\section{CONCLUSION}

A Continuum Damage Mechanics model is developed for CMCs which is mechanismsbased. When applied to $\mathrm{SiC} / \mathrm{SiC}(0,90)$ lay-ups, the present model has ten internal variables, viz. three inelastic strains modeling debonding, three damage variables describing the amount of debonding and four damage variables accounting for matrix-cracking in the two plies and fiberbreakage. Only two different experiments in tension are needed to identify the growth laws of the twelve internal variables. The laws which relate the growth of the internal state variables to their associated forces have been derived from tensile loading-unloading experiments for two different directions in the $0 / 90$ and \pm 45 fiber configurations.

The ability of the model to be extended to fatigue and creep conditions suggests the advantage of a mechanisms-based approach. The extension in fatigue involves one type of test, which can be either a cyclic tensile test or a four-point bend test. The only variables to modify are the inelastic strains with respect to the number of cycle. When creep is concerned, the kinetics of the three creep strains can be identified by using 4 different types of creep tests.

The results on the plate with a hole under cyclic loading conditions, are compared to experimental measurements. They show a good correlation in terms of strain level measured at 
different points of the specimen. These fatigue tests have been performed up to 1 million cycles and exhibit a reduction by $20 \%$ of the maximum normal stress in the ligament. The creep simulations done on a specimen of the same geometry revealed a major redistribution of the normal stress along the ligament for a loading configuration at \pm 45 degrees and at a temperature of $1200^{\circ} \mathrm{C}$ and very little redistribution at a temperature of $980^{\circ} \mathrm{C}$.

This paper shows how to derive from a monotonic-based constitutive equation a simple extension to cyclic and/or creep loading conditions. However, this derivation is only possible if the construction of the constitutive law relies on analyses based upon well-identified degradation mechanisms. Isofatigue and isochronous analyses were used to analyze complex loading conditions. This techniques gives a much faster answer to designers and engineers than regular constitutive equations that go over the complete loading history. Consequently, designers can analyze more solutions in the same time and should be more efficient in their final design choice.

\section{REFERENCES}

1. J. Aveston, G. A. Cooper and A. Kelly, Proc. National Physical Laboratory: Properties of Fiber Composites, IPC Science and Technology Press, Surrey (UK), pp. 15-26, 1971.

2. D. Rouby and P. Reynaud, Fatigue Behaviour Related to Interface Modification During Load Cycling in Ceramic-Matrix Fibre Composites, Comp. Sci. Tech., vol. 48, pp. 109-118, 1993.

3. F. Hild, A. Burr and F. A. Leckie, Fiber Breakage and Fiber Pull-Out of Fiber-Reinforced Ceramic-Matrix Composites, Eur. J. Mech. A/Solids, vol. 13 [6], pp. 731-749, 1994.

4. C. H. Weber, J. P. A. Löfvander and A. G. Evans, The Creep Anisotropy of a ContinuousFiber-Reinforced Silicon Carbide Calcium Aluminosilicate Composite, J. Am. Ceram. Soc., vol. 77 [7], pp. 1745-1752, 1994.

5. J.-M. Domergue, Relationships between the Macroscopic Behavior of Ceramic Matrix Composites and their Constituents Properties, $\mathrm{PhD}$ thesis, University of California, Santa Barbara, 1995. 
6. F. Hild, A. Burr and F. A. Leckie, Matrix Cracking and Debonding in Ceramic-Matrix Composites, Int. J. Solids Struct., vol. 33 [8], pp. 1209-1220, 1996.

7. D. Beyerle, S. M. Spearing, F. W. Zok and A. G. Evans, Damage, Degradation and Failure in a Unidirectional Ceramic-Matrix Composite, J. Am. Ceram. Soc., vol. 75 [10], pp. 2719$2725,1992$.

8. A. W. Pryce and P. A. Smith, Modelling of the Stress/Strain Behavior of Unidirectional Ceramic Matrix Composite Laminates, J. Mater. Sci., vol. 27, pp. 2695-2704, 1992.

9. J. Lemaitre, A Course on Damage Mechanics, Springer-Verlag, Berlin (Germany), 1992.

10. A. Burr, F. Hild and F. A. Leckie, Continuum Description of Damage in Ceramic-Matrix Composites, Eur. J. Mech. A/Solids, vol. 16 [1], pp. 53-78, 1997.

11. A. Burr, F. Hild and F. A. Leckie, Micro-Mechanics and Continuum Damage Mechanics, Arch. Appl. Mech., vol. 65 [7], pp. 437-456, 1995.

12. D. Boudon-Cussac, A. Burr and F. Hild, in Damage Mechanics in Engineering Materials, Studies in Applied Mechanics, Elsevier, Amsterdam (the Netherlands), pp. 303-320, 1998.

13. A. Burr, F. Hild and F. A. Leckie, Continuum Description of Damage in Ceramic-Matrix Composites, Eur. J. Mech. A/Solids, vol. 16 [1], pp. 53-78, 1997.

14. A. Burr, Micromécanique et comportement de matériaux hétérogènes, $\mathrm{PhD}$ thesis, Université Paris 6, 1995.

15. A. G. Evans, F. W. Zok and R. M. McMeeking, Fatigue of Ceramic Matrix Composites, Acta Metall. Mater., vol. 43 [3], pp. 859-875, 1995.

16. A. Burr and F. Hild, Ultimate Tensile Strength during Fatigue of Fiber-Reinforced CeramicMatrix Composites, Mech. Res. Comm., vol. 22 [4], pp. 401-406, 1995.

17. A. Burr, F. Hild and F. A. Leckie, The Mechanical Behaviour under Cyclic Loading of Ceramic-Matrix Composites, Mater. Sci. Eng., vol. A250 [2], pp. 256-263, 1998.

18. H. D. Hibbitt, B. I. Karlsson and P. Sorensen, Abaqus, User's Manual, version 5.6, 1996.

19. A. Burr, F. Hild and F. A. Leckie, in D. McDowell (ed.), Damage, Fatigue and Failure of Ceramic-Matrix Composites, ASTM, Philadelphia, PA (USA), pp. 83-94, 1997. 
20. A. C. F. Cocks and F. A. Leckie, in J. W. Hutchinson and T. Y. Wu (ed.), Creep Constitutive Equations for Damaged Materials, vol. 25, Academic Press, New-York, NY (USA), pp. 239-294, 1987.

21. Z. Z. Du, A. C. F. Cocks and R. M. McMeeking, Power-law Matrix Creep in Fiber Composites due to Transverse Stress Gradient, Eur. J. Mech., A/Solids, vol. 16 [3], pp. 445, 1997.

22. A. C. F. Cocks and A. A. Searle, Cavity Growth in Ceramic Materials under Multiaxial Stress States, Report 89/1, Leicester University - Engineering Department, 1989.

23. J. A. DiCarlo, B. Janet, J. B. Hurst, G. N. Moracher, A. Sayer and G. Selover, Proc. of the Third Annual HITEMP Review, Paper 50-1, 1990. 
7. APPENDIX 1: MATERIAL PARAMETERS FOR A SiC/SiC COMPOSITE

\begin{tabular}{|c|c|c|c|}
\hline Material parameter & & Value & Unit \\
\hline Matrix elastic Modulus & $\mathrm{E}_{\mathrm{m}}$ & 157 & GPa \\
\hline Matrix Poisson's ratio & $v_{\mathrm{m}}$ & 0.25 & \\
\hline Matrix volume fraction & $\mathrm{f}_{\mathrm{m}}$ & 0.55 & \\
\hline Weibull modulus & $\mathrm{m}_{\mathrm{m}}$ & 1.6 & \\
\hline Normalizing energy & $\mathrm{Y}_{\mathrm{m} 0}$ & 0.60 & $\mathrm{MPa}$ \\
\hline Saturation parameter & $\mathrm{D}_{\text {sat }}$ & 0.99 & \\
\hline Fiber elastic modulus & $\mathrm{E}_{\mathrm{f}}$ & 200 & $\mathrm{GPa}$ \\
\hline Fiber Poisson's ratio & $v_{\mathrm{f}}$ & 0.25 & \\
\hline Fiber volume fraction & $f_{f}$ & 0.45 & \\
\hline Weibull modulus & $\mathrm{m}_{\mathrm{f}}$ & 4.5 & \\
\hline Normalizing energy & $\mathrm{Y}_{\mathrm{fO}}$ & 42.5 & MPa \\
\hline Tensile inelastic strain constant & $\varepsilon_{\text {int }}$ & $4.9910^{-5}$ & \\
\hline Threshold tensile stress & $\sigma_{\text {th }}$ & 135 & $\mathrm{MPa}$ \\
\hline Exponent & $\mathrm{n}_{\mathrm{ii}}$ & 1.0 & \\
\hline Shear inelastic strain constant & $\varepsilon_{\text {ins }}$ & $5.010^{-5}$ & \\
\hline Threshold shear stress & $\tau_{\text {th }}$ & 59.1 & $\mathrm{MPa}$ \\
\hline Exponent & $\mathrm{n}_{12}$ & 2.0 & \\
\hline Fatigue amplitude & $\gamma$ & 0.984 & \\
\hline Normalizing value & a & 6.96 & \\
\hline Exponent & $\mathrm{n}$ & 1.56 & \\
\hline Time power law exponent & $\mathrm{n}_{\mathrm{t}}$ & 0.451 & \\
\hline Normalizing time & $t_{i 0}$ & 70.2 & $\mathrm{~h}$ \\
\hline Shear creep strain constant & $\varepsilon_{120}$ & $1.3510^{-3}$ & \\
\hline Temperature coefficient & $\mathrm{b}$ & 28.1 & \\
\hline Stress power law exponent & $\mathrm{n}_{\sigma}$ & 4.2 & \\
\hline Time power law exponent & $\mathrm{n}_{\mathrm{s}}$ & 0.4 & \\
\hline Normalizing temperature & $\mathrm{T}_{0}$ & 1204 & ${ }^{\circ} \mathrm{C}$ \\
\hline Normalizing stress & $\tau_{0}$ & 34.5 & $\mathrm{MPa}$ \\
\hline Normalizing time & $\mathrm{t}_{120}$ & 100 & $\mathrm{~h}$ \\
\hline
\end{tabular}




\section{FIGURE CAPTIONS}

Figure 1: Comparison of maximum and minimum inelastic strains experimentally measured and predicted by the model.

Figure 2: Normal stress profile across the thickness in a 4 point bend test for an elastic and non-linear computation when $\mathrm{N}=0$ and $\mathrm{N}=300000$.

Figure 3: (a) Comparison of strains between experiment and computations of a test on a plate with a hole. (b) Strain gauge location in the experiment.

Figure 4: Stress profile along the ligament of a plate with a hole tested in fatigue.

Figure 5 : Stress redistribution in creep of a plate with a hole $\left(\mathrm{T}=980^{\circ} \mathrm{C}\right)$.

Figure 6: Stress redistribution in creep of a plate with a hole $\left(\mathrm{T}=1200^{\circ} \mathrm{C}\right)$. 


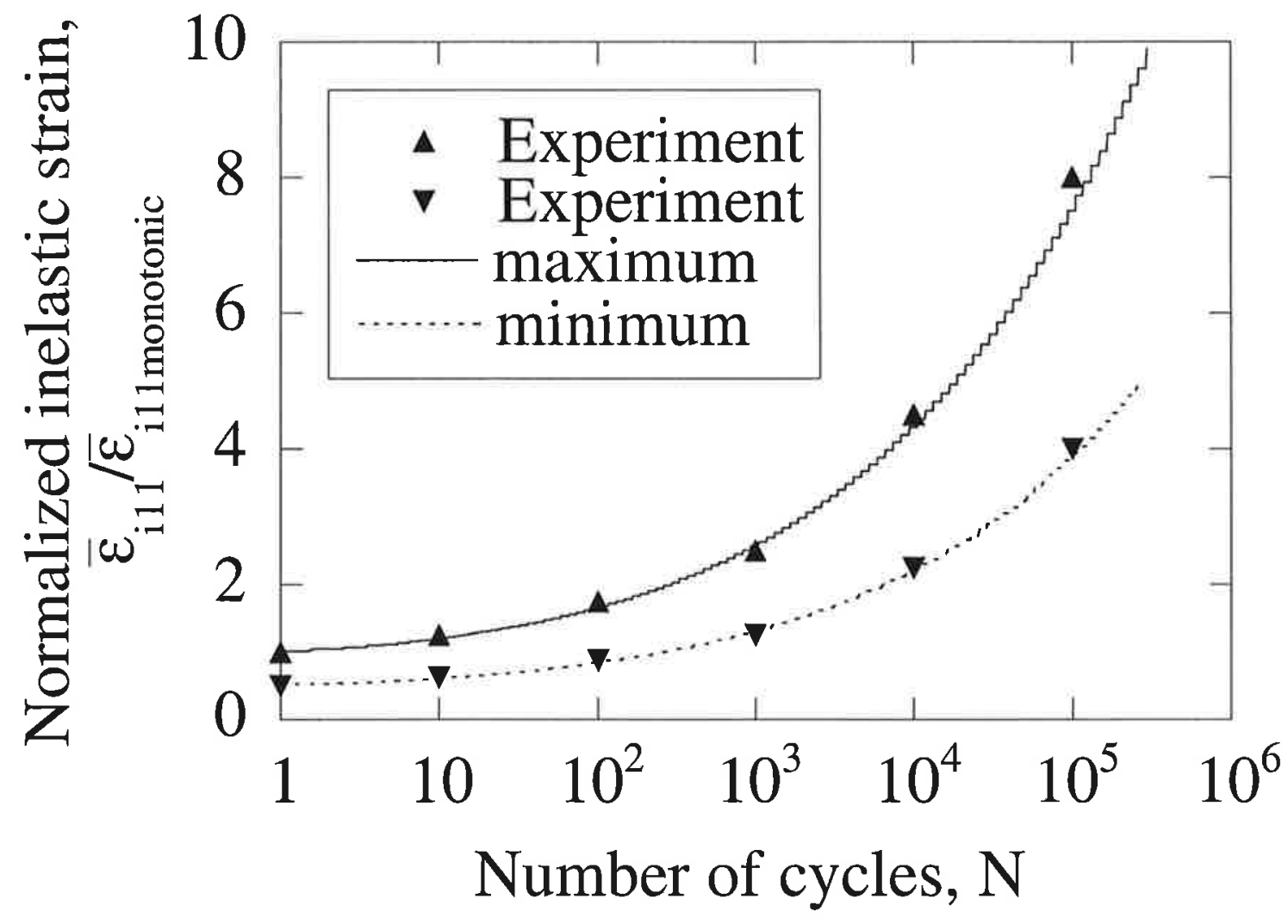

Figure 1: Burr et al. 


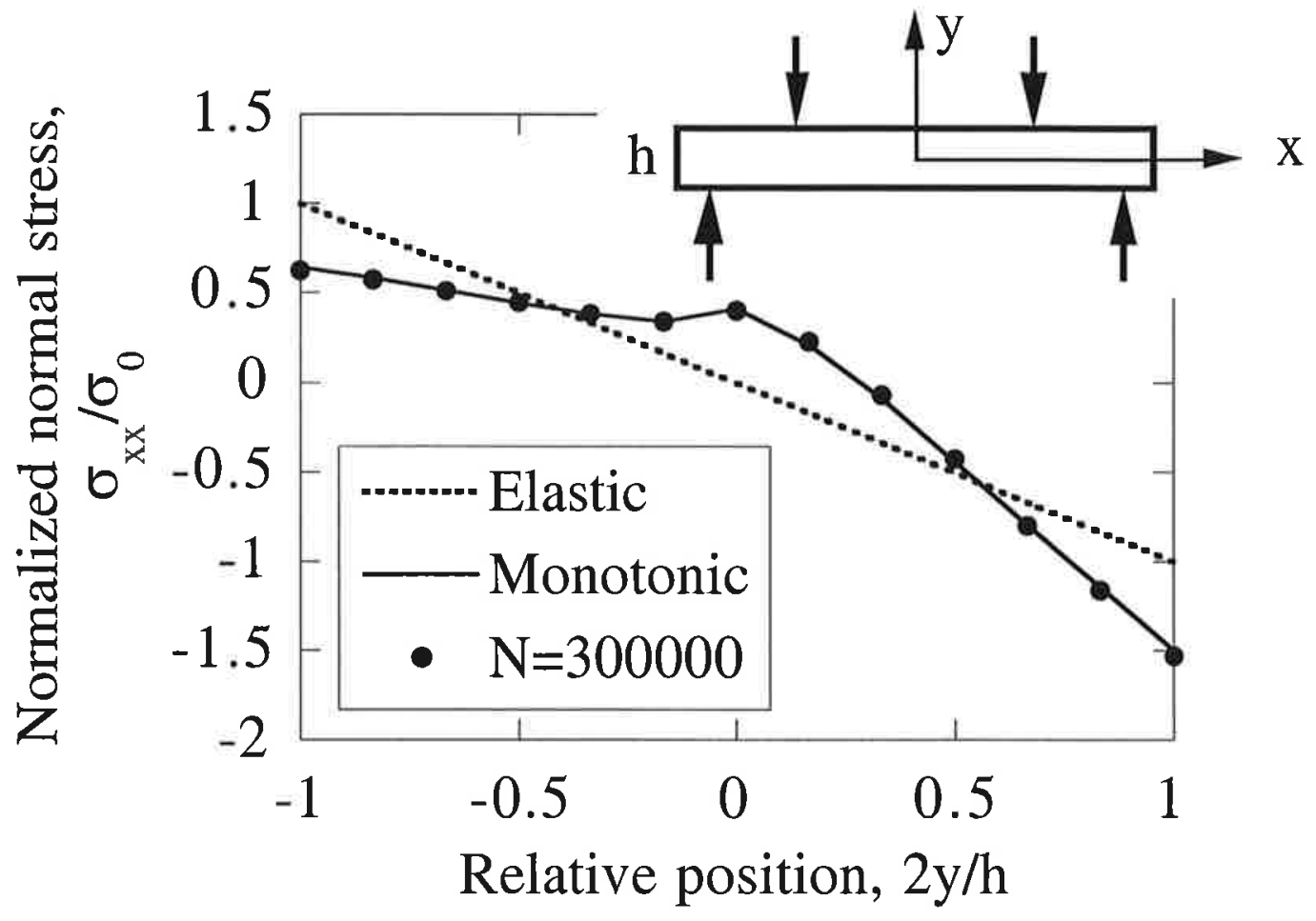

Figure 2: Burr et al. 


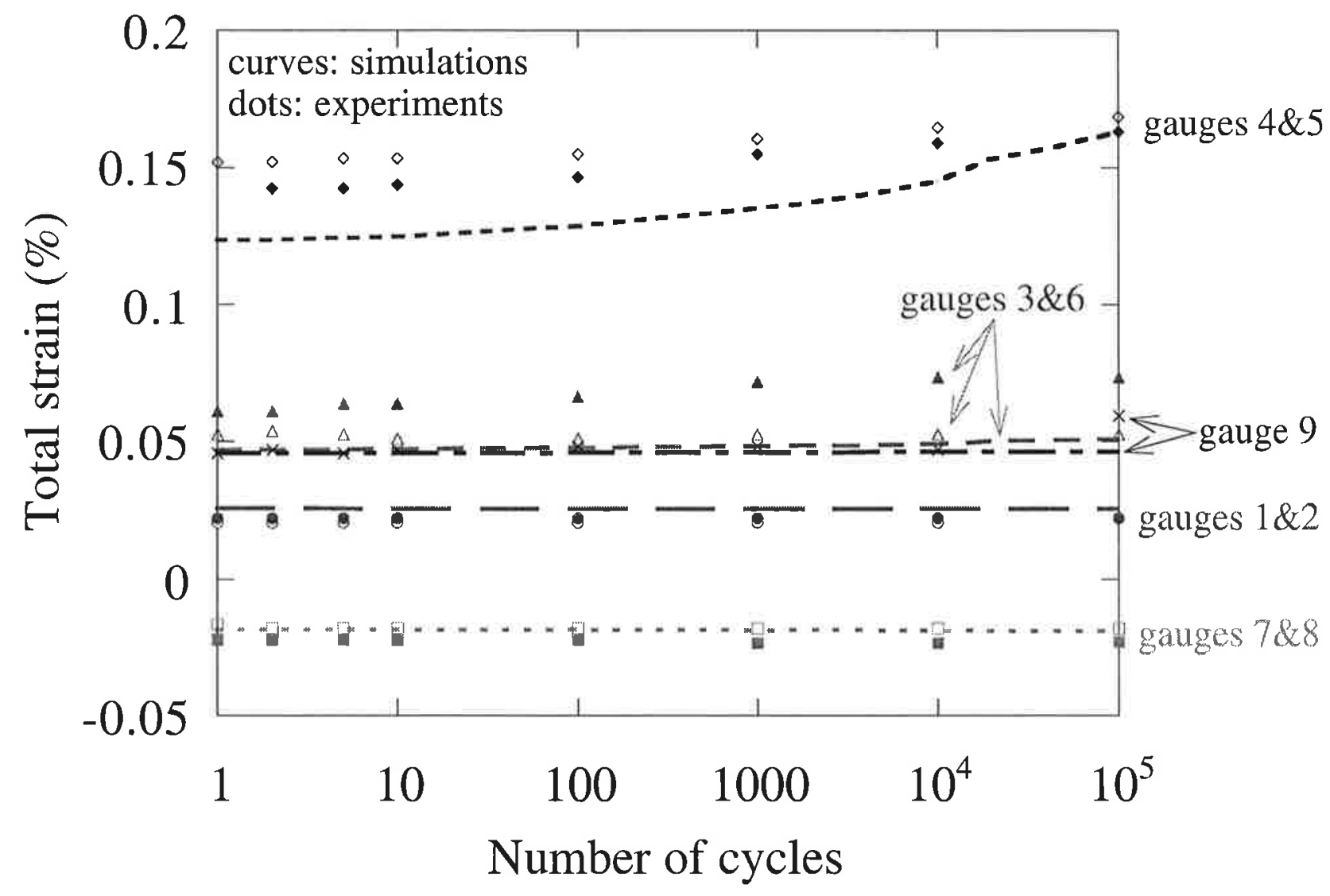

Figure 3a: Burr et al. 


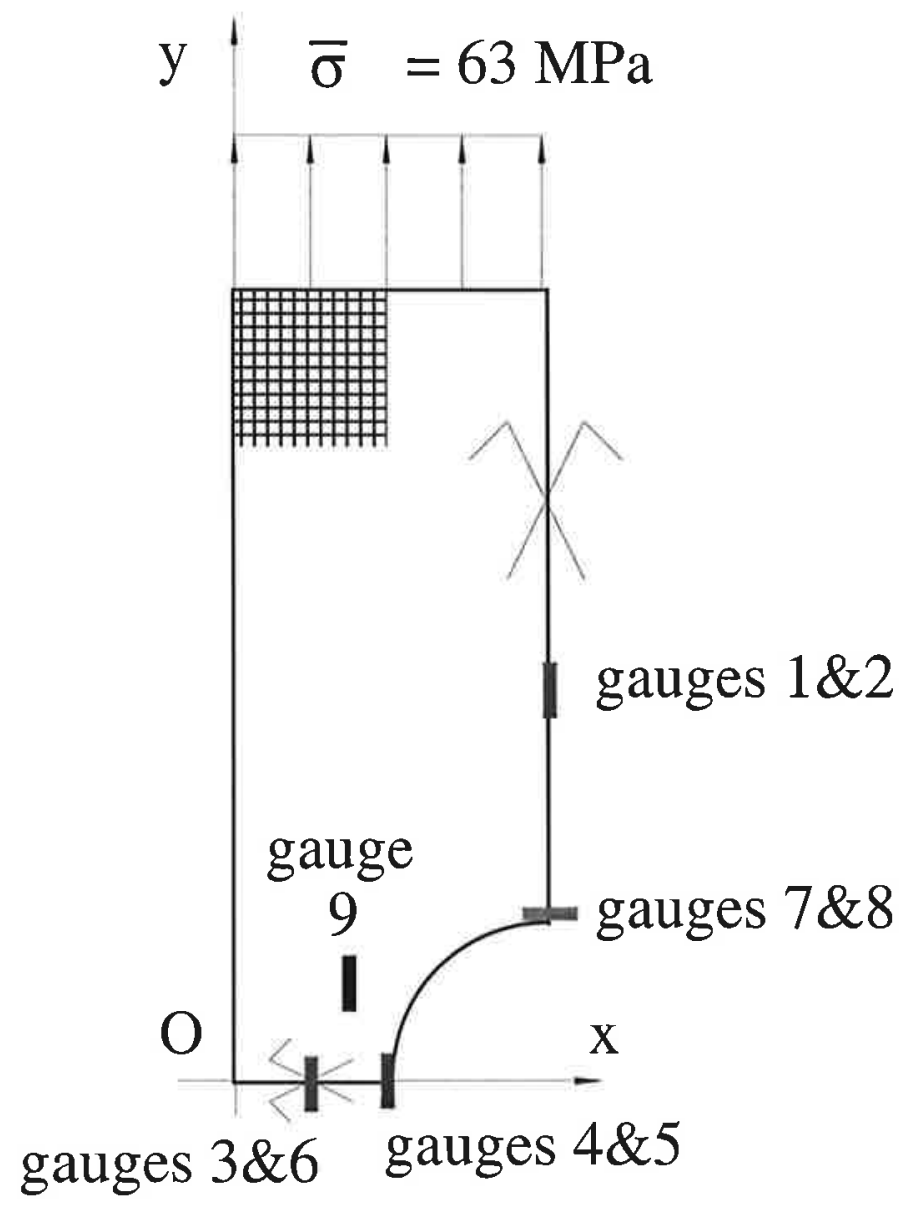

Figure 3b: Burr et al. 


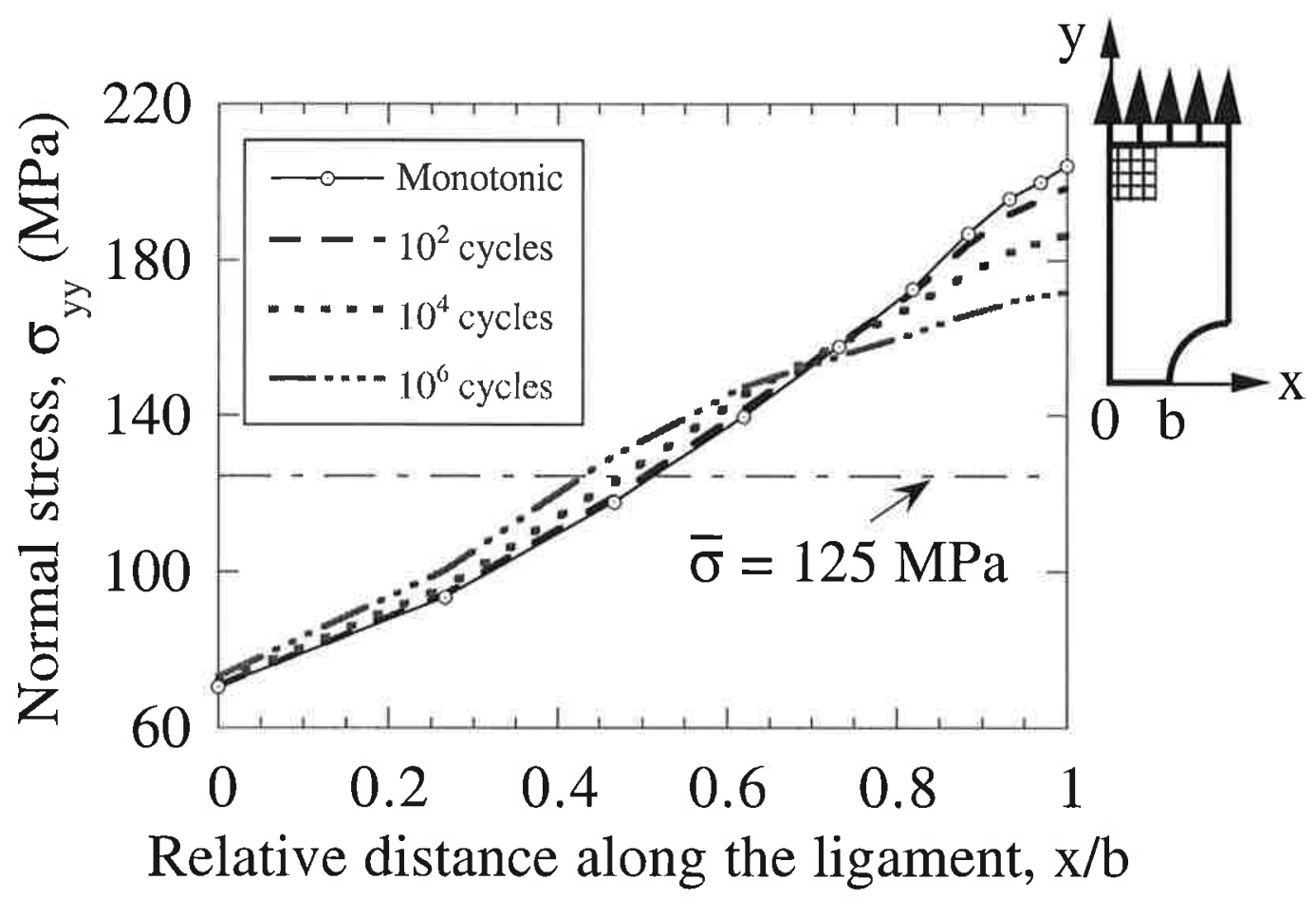

Figure 4: Burr et al. 


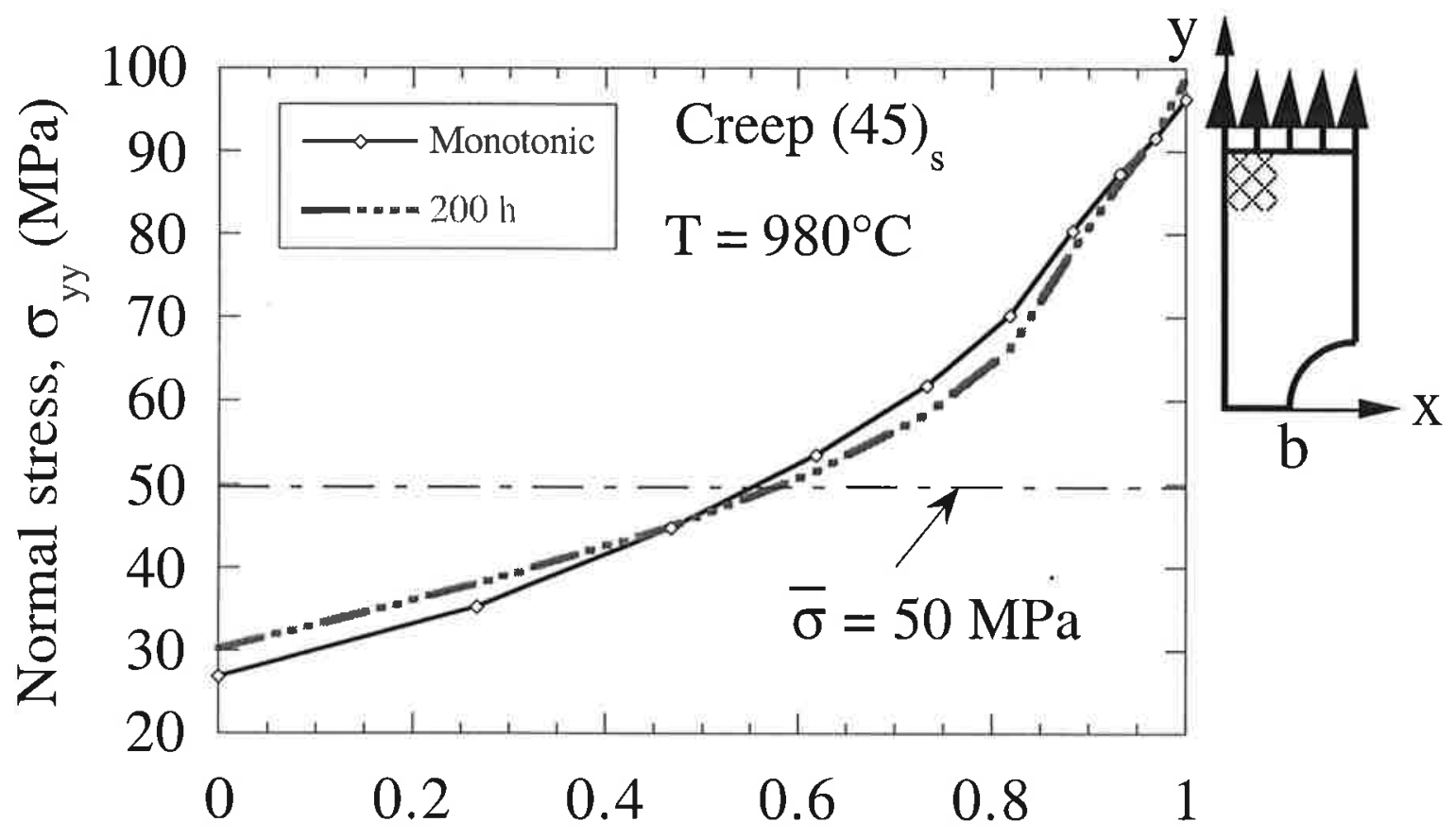

Relative distance along the ligament, $\mathrm{x} / \mathrm{b}$

Figure $5:$ Burr et al. 


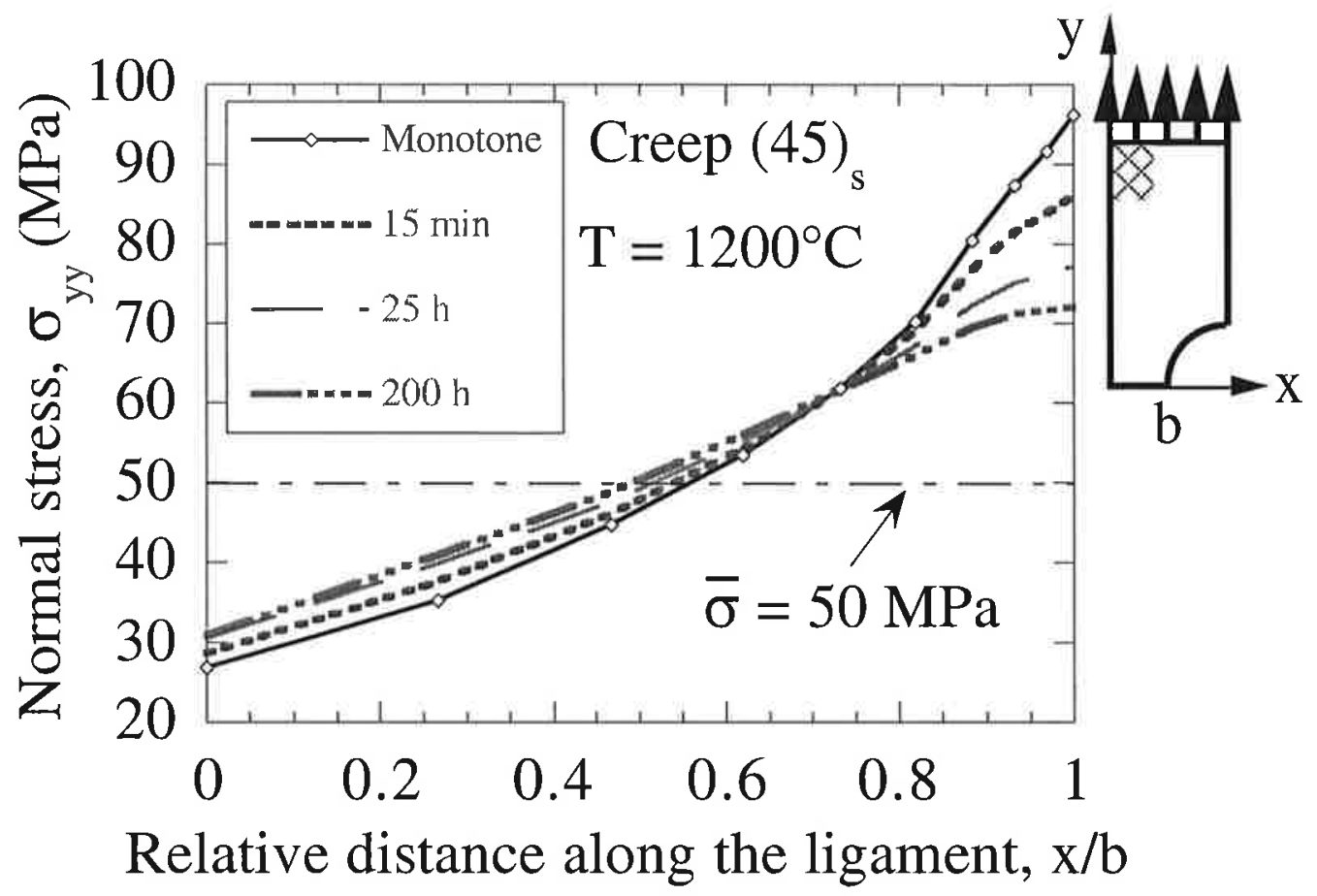

Figure 6: Burr et al. 